\title{
TINGKAT PENGETAHUAN PASIEN TENTANG PELAYANAN BPJS KESEHATAN PADA ERA JKN DI PUSKESMAS CEMPAKA KOTA BANJARMASIN
}

\author{
THE LEVEL OF PATIENT'S KNOWLEDGE ABOUT \\ BPJS KESEHATAN SERVICE IN JKN ERA \\ IN THE CEMPAKA HEALTH CENTER OF THE \\ BANJARMASIN CITY
}

\author{
Noverda Ayuchecaria ${ }^{* *}$, Eka Rahmadania, Riza Alfian, Saftia Aryzki \\ Akademi Farmasi ISFI Banjarmasin \\ Jl. Flamboyan III No.7B, Sungai Miai, Kota Banjarmasin
}

Submitted : 9 August 2019

Reviewed : 23August 2019

Accepted: 12 September 2019

\begin{abstract}
ABSTRAK
Pengetahuan tentang BPJS sangat memegang peranan penting dalam keberhasilan program BPJS itu sendiri. Pengetahuan pasien yang baik diharapkan dapat mempermudah pelaksanaan program-program BPJS. Salah satu bagian terpenting pada program BPJS adalah pelayanan kefarmasian. Fakta dilapangan belum ada data yang menunjukkan sejauh mana pengetahuan pasien tentang program BPJS khususnya yang menyangkut pelayanan kefarmasian. Penelitian ini bertujuan untuk mengetahui tingkat pengetahuan pasien tentang pelayanan BPJS Kesehatan pada era JKN di Puskesmas Cempaka Kota Banjarmasin.

Jenis penelitian ini adalah penelitian observasional. Pengambilan data dilakukan dari tanggal 15 April 2019 sampai 22 Mei 2019 di Puskesmas Cempaka Kota Banjarmasin. Sampel pada penelitian ini berjumlah 358 responden dan diambil menggunakan teknik purposive sampling. Pengumpulan data dilakukan dengan menggunakan kuesioner yang terdiri dari 16 pertanyaan. Kuesioner telah di uji validitas dan reliabilitas yang dinyatakan valid dan reliabel. Data hasil penelitian dianalisis dengan menggunakan rumus persentase dan dinyatakan dalam bentuk persen disetiap parameter tingkat pengetahuan.

Hasil penelitian menunjukan responden berpengetahuan cukup sebanyak 176 orang $(49,16 \%)$, sedangkan berpengetahuan baik sebanyak 141 orang $(39,39 \%)$ dan berpengetahuan kurang sebanyak 41 orang $(11,45 \%)$. Pada tiap parameter yang diuji, persentase tingkat pengetahuan tertinggi adalah parameter iuran $(86,29 \%$; Kategori Baik) sedangkan persentase tingkat pengetahuan terendah terletak pada parameter pelayanan obat (67,12\%; Kategori Cukup).
\end{abstract}

Kata Kunci : Peserta BPJS, BPJS Kesehatan, JKN, Tingkat Pengetahuan

\begin{abstract}
The knowledge of BPJS plays an important role in the success of BPJS program itself. Good patient knowledge is expected to facilitate the implementation of BPJS programs. One of the most important parts of the BPJS program is the Ministry of Pharmacy. The fact in the field has no data indicating the extent of the patient's knowledge of BPJS program in particular involving the Ministry of Pharmacy. This study aims to determine the
\end{abstract}


level of patient knowledge about BPJS Kesehatan services in the JKN era at the Cempaka Health Center in Banjarmasin City.

This type of research is observational research. Data retrieval conducted from 15 April 2019 until 22 May 2019 at Cempaka Puskesmas in Banjarmasin City. The samples in this study amounted to 358 respondents and were taken using purposive sampling techniques. Data collection is done using a questionnaire consisting of 16 questions. Questionnaires have been tested for validity and reliability. The research result Data is analyzed by using the percentage formula and expressed in percent form in each knowledge level parameter.

The result showed as many as 176 respondents $(49,16 \%)$ have sufficient knowledge; 141 respondents $(39,39 \%)$ have good knowledge and 41 respondent $(11,45 \%)$ have less knowledge. In each parameter tested, the highest percentage of knowledge level is the contribution parameter (86.29\%; Good Category) while the lowest level of knowledge lies in the drug service parameters (67.12\%; Enough Category).

Keywords : BPJS Participants, BPJS, JKN, Knowledge Level.

\section{Penulis korespondensi:}

Noverda Ayuchecaria

Akademi Farmasi ISFI Banjarmasin

Jl. Flamboyan III No.7B, Sungai Miai, Kota Banjarmasin

Email : noverdaayu24@gmail.com / 082220711818

\section{PENDAHULUAN}

Badan Penyelenggara Jaminan Sosisal (BPJS) kesehatan merupakan program Jaminan Kesehatan Nasional yang bertujuan untuk memenuhi kebutuhan kesehatan masyarkat yang layak yang diberikan kepada setiap orang yang telah membayar iuran atau iurannya dibayar oleh Pemerintah (Eky, 2015). Sampai sekarang, perserta JKN cenderung meningkat setiap bulannya.

Melihat banyaknya jumlah peserta JKN, pemahaman peserta tentang fungsi BPJS menjadi suatu hal yang penting untuk diperhatikan hal ini bertujuan agar pelayanan BPJS kepada masyarakat terselenggara dengan lebih efisien. Pengetahuan pasien yang baik diharapkan dapat mempermudah pelaksanaan program-program BPJS. Salah satu bagian terpenting pada program BPJS adalah pelayanan kefarmasian, yang merupakan pelayanan utama yang berada dibawah naungan program JKN. Setiap peserta yang berobat pasti mendapatkan obat, pemerintah sendiri telah menjamin ketersediaan dan keterjangkauan obat yang sesuai dengan formularium nasional dan besarannya sesuai dengan e-catalogue (Kemenkes, 2014). Oleh karena itu, pemberian pelayanan kefarmasian yang baik dapat meningkatkan keberhasilan dari program JKN.

Puskesmas sendiri menjadi salah satu fasilitas kesehatan yang paling banyak melakukan pelayanan kepada peserta BPJS (BPJS Kesehatan, 2018). Berdasarkan latar belakang tersebut menarik minat peneliti untuk meneliti tentang tingkat pengetahuan pasien tentang pelayanan BPJS kesehatan pada era JKN di Puskesmas Cempaka Kota Banjarmasin.

\section{METODE PENELITIAN \\ Instrumen Penelitian}

Instrumen yang digunakan dalam penelitian ini berupa lembar kuesioner yang diberikan kepada pasien yang memenuhi syarat serta telah mengisi informed consent.

\section{Jalannya Penelitian}

Penelitian ini menggunakan penelitian observasional untuk menegtahuan tingkat pengetahuan pasien tentang pelayanan BPJS Kesehatan di Puskesmas Cempaka Kota 
Banjarmassin. Penelitian dilakukan di Puskesmas Cempaka Banjarmasin pada bulan AprilMei 2019. Populasi dalam penelitian ini adalah pasien BPJS yang melakukan pengambil obat di Puskesmas Cempaka Kota Banjarmasin. Sampel yang diambil atau diteliti adalah pasien BPJS yang melakukan pengambilan obat pada waktu penelitian berlangsung yang memenuhi syarat. Teknik pengambilan sampel yang digunakan yaitu purposive sampling. Jumlah populasi dalam penelitian ini telah diketahui dari data tahun lalu sehingga pengambilan sampel yang diperlukan dalam penelitian ini menggunakan rumus slovin (Nursalam, 2008).

Rumus Slovin :

$$
\mathrm{n}=\frac{N}{1+N e^{2}}
$$

Keterangan :

$$
\begin{aligned}
& \mathrm{N}=\text { jumlah sampel } \\
& \mathrm{N}=\text { jumlah populasi } \\
& \mathrm{e}=\text { Presisi yang ditetapkan }(\mathrm{e}: 0,05)
\end{aligned}
$$

Dengan menggunakan rumus slovin 358 sampel dengan tingkat kesalahan 5\%. Data yang diperoleh dianalisis dengan menggunakan rumus persentase.

\section{HASIL DAN PEMBAHASAN}

Karakteristik responden menjawab pertanyaan yang di berikan peneliti didapat bahwa mayoritas responden yang berperan serta dalam penelitian ini berumur $>50$ sebanyak 87 responden $(24,30 \%)$, dengan mayoritas responden berjenis kelamin perempuan sebanyak 215 responden $(60,06 \%)$.

Pada data tersebut juga diketahui bahwa mayoritas responden berada pada kelompok pendidikan terakhir SMA sebanyak 203 responden (56,70\%), dan responden yang berperan serta dalam penelitian memiliki pekerjaan sebagai Ibu Rumah Tangga sebanyak 161 responden $(44,97 \%)$ dan paling sedikit bekerja sebagai Pegawai Negeri Sipil sebanyak 10 responden $(2,79 \%)$. 
Tabel 1. Karakteristik Responden

\begin{tabular}{clcc}
\hline \multirow{2}{*}{ Karakteristik Pasien } & \multicolumn{2}{c}{ Subjek Peneliti } \\
\cline { 2 - 4 } & $\leq 20$ Tahun & $(\mathrm{n}=358)$ & $8,66 \%$ \\
& $21-30$ Tahun & 31 & $22,07 \%$ \\
& $31-40$ Tahun & 79 & $23,74 \%$ \\
& $41-50$ Tahun & 85 & $21,23 \%$ \\
& $>$ 50 Tahun & 76 & $24,30 \%$ \\
\hline \multirow{3}{*}{ Jenis Kelamin } & Laki-Laki & 87 & $39,94 \%$ \\
& Perempuan & 143 & $60,06 \%$ \\
\hline \multirow{5}{*}{ Pendidikan } & Tidak Bersekolah & 215 & $2,23 \%$ \\
& SD & 8 & $11,61 \%$ \\
& SMP & 38 & $17,88 \%$ \\
& SMA & 64 & $56,70 \%$ \\
& Akademi/Perguruan Tinggi & 203 & $12,57 \%$ \\
\hline \multirow{6}{*}{ Pekerjaan } & Tidak Bekerja & 45 & $12,01 \%$ \\
& Ibu Rumah Tangga & 43 & $44,97 \%$ \\
& Pedagang/Wiraswasta & 64 & $17,88 \%$ \\
& Pegawai Negeri Sipil & 10 & $2,79 \%$ \\
& Pegawai Swasta & 80 & $22,35 \%$ \\
\hline
\end{tabular}

Sumber : Data Primer; Keterangan : $\mathrm{n}=$ jumlah sampel; $\%=$ jumlah total

Pengukuran tingkat pengetahuan pasien tentang pelayanan BPJS Kesehatn dalam penelitian ini dilakukan dengan cara menghitung skor yang berasal dari banyaknya jumlah pertanyaan yang dapat dijawab oleh responde. Dari hasil skoring didapatkan hasil pada gambar I menunjukkan dari 358 responden dalam penelitian ini, 141 responden diantaranya memiliki pengetahuan baik $(39,39 \%), 176$ responden berpengetahuan cukup $(49,16 \%)$ dan 41 responden dinyatakan berpengetahuan kurang (11,45\%). Berdasarkan hasil tersebut bahwa sebagian besar responden memiliki pengetahuan cukup tentang pelayanan kefarmasian pada era JKN di Puskesmas Cempaka Kota Banjarmasin. Hal ini ada beberapa faktor yang mempengaruhi pengetahuan responden tentang pelayanan BPJS Kesehatan era $\mathrm{JKN}$, antara lain faktor lupa atau kurang menyimak informasi yang disampaikan petugas BPJS maupun pihak Puskesmas, serta kurangnya pengalaman responden dalam memanfaatkan pelayanan yang diberikan (Disasatra, 2016).

Terlepas dari berbagai macam faktor yang mempengaruhi pengetahuan pasien. Pasien BPJS pada Puskesmas Cempaka Banjarmasin yang berpengatahuan lebih tinggi juga dikarenakan adanya pengalaman dalam pengaplikasian program BPJS dalam pelayanan kefarmasin secara langsung. Sepertihalnya mendapatkan fasilitas rujukkan ke Rumah Sakit, program rujuk balik, serat melakukan iuran secara personal. Menurut Budiman dan Riyanto (2013), menyatakan bahwa Pengalaman seseorang tentang suatu permasalahan akan membuat orang tersebut mengetahui bagaimana cara menyelesaikan permasalahan dari pengalaman sebelumnya yang telah dialami sehingga pengalaman yang didapat bisa dijadikan sebagai pengetahuan apabila medapatkan masalah yang sama. 


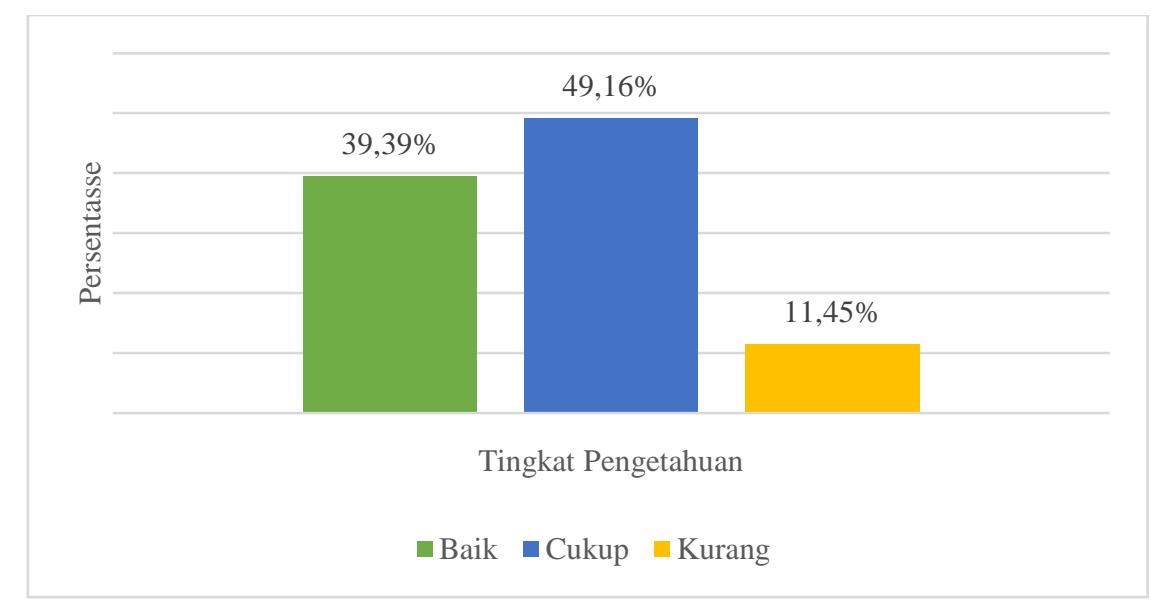

Gambar 1. Tingkat Pengetahuan Pasien Tentang Pelayanan BPJS Kesehatan Pada Era JKN di Puskesmas Cempaka Kota Banjarmasin ( $\mathrm{n}=358)$

Tabel 2. Tingkat Pengetahuan Pasien Tiap Item Pernyataan

\begin{tabular}{|c|c|c|c|}
\hline Parameter & Nomor Pernyataan & $\begin{array}{c}\text { Benar }(\%) \\
(\mathrm{n}=385)\end{array}$ & $\begin{array}{c}\text { Salah }(\%) \\
(\mathrm{n}=385)\end{array}$ \\
\hline \multirow{4}{*}{ Sistem Rujukan } & Pernyataan 1 & $94,41 \%$ & $5,59 \%$ \\
\hline & Pernyataan 2 & $74,02 \%$ & $25,98 \%$ \\
\hline & Pernyataan 3 & $63,41 \%$ & $36,59 \%$ \\
\hline & Pernyataan 4 & $62,57 \%$ & $37,43 \%$ \\
\hline \multirow{3}{*}{ Program Rujuk Balik } & Pernyataan 5 & $86,31 \%$ & $13,69 \%$ \\
\hline & Pernyataan 6 & $82,40 \%$ & $17,60 \%$ \\
\hline & Pernyataan 7 & $62,29 \%$ & $37,71 \%$ \\
\hline \multirow{7}{*}{ Pelayanan Obat } & Pernyataan 8 & $60,61 \%$ & $39,39 \%$ \\
\hline & Pernyataan 9 & $90,78 \%$ & $9,22 \%$ \\
\hline & Pernyataan 10 & $95,53 \%$ & $4,47 \%$ \\
\hline & Pernyataan 11 & $71,23 \%$ & $28,77 \%$ \\
\hline & Pernyataan 12 & $66,20 \%$ & $33,80 \%$ \\
\hline & Pernyataan 13 & $42,18 \%$ & $57,82 \%$ \\
\hline & Pernyataan 14 & $47,21 \%$ & $52,79 \%$ \\
\hline \multirow{2}{*}{ Iuran } & Pernyataan 15 & $87,15 \%$ & $12,85 \%$ \\
\hline & Pernyataan 16 & $86,87 \%$ & $13,13 \%$ \\
\hline
\end{tabular}

Berdasarkan hasil penelitian yang dapat dilihat pada Tabel 2 menunjukkan bahwa pernyataan nomor 8 tentang pasien BPJS dapat menebus obat diseluruh Apotek. Pada pernyataan ini mendapatkan hasil persentase jawaban salah yang tinggi $(39,39 \%)$. Pasien masih banyak yang membenarkan pernyataan diatas. Padahal tidak semua Apotek menerima resep pasien BPJS, hanya Apotek tertentu yang menjalin kerjasama dengan pihak BPJS. Seharusnya pasien diberikan infomasi Apotek mana saja yang menjalin kerjasama langsung dengan BPJS. Adapun beberapa persyaratan apotek untuk berjasama dengan BPJS yaitu surat ijin apotek, surat ijin praktek apoteker, surat ijin kerja tenaga teknis kefarmasian, perjanjian kerja sama dengan jejaring dan surat tanda kerja sama dengan dokter maupun klinik (BPJS, 2015).

Pada pernyataan kedua nomor 13 tentang BPJS Kesehatan dapat melayani semua jenis penyakit. Banyak pasien yang masih membenarkan hal ini, terlihat dari hasil jawaban pernyataan pada tabel 4.5 sebanyak $(57,82 \%)$ menjawab salah. Padahal dalam pernyataan ini 
tidak semua jenis penyakit di tanggung oleh BPJS Kesehatan. Masih ada beberapa penyakit yang belum di tanggung oleh BPJS Kesehatan ataupun sekedar dibatasi pelayanannya, seperti penyakit atau gangguan kesehatan akibat ketergantungan obat-obatan atau akohol, pelayanan ortodontis, dan beberapa penyakit kronis yang sekarang tidak lagi ditanggung 100\% oleh BPJS Kesehatan (jantung, gagal ginjal, kanker, strok, sirosis hepatitis, thalassemia, leukimia, dan hemofilia). Selain itu BPJS sendiri sudah memberikan informasi tentang penyakit apa saja yang ditanggung oleh BPJS. Sampai sekarang tercatat hanya 155 penyakit yang telah ditanggung oleh BPJS Kesehatan di fasilitas kesehatan tingkat pertama (BPJS Kesehatan, 2018).

Pernyataan selanjutnya nomor 14, seluruh obat ditanggung oleh BPJS Kesehatan, mempunyai hasil persentase responden yang menjawab salah sebanyak 52,78\%. Masih banyak pasien yang beranggapan kalau semua obat ditanggung oleh BPJS Kesehatan. Hal ini karena pasien tidak diinformasikan serta pasien tidak memiliki daftar obat apa saja yang ditanggung oleh BPJS, kebanyakan setelah berobat pasien baru mengetahui jika ada obat yang tidak ditanggung. Obat yang ditanggung oleh BPJS sebenarnya juga sudah terdaftar dalam Formularium Nasional. Pedoman tersebut juga sudah ditetapkan oleh tim komite nasional penyusunan formularium nasional dan menteri kesehatan RI melalui keputusan menteri kesehatan. Pedoman ini pun sudah di pakai dalam seluruh pelayanan kesehatan. Sedangkan yang tidak ditanggung oleh BPJS biasanya obar jarang digunakan, risk-benfit yang belum jelas, regulasi yang tidak memenuhi untuk di berikan, dan kekosongan obat.

\section{KESIMPULAN}

Berdasarkan hasil penelitian yang dilaksanakan di Puskesams Cempaka Kota Banjarmasin terhadap 358 pasien yang bertindak sebagai responden, dapat diambil kesimpulan tingkat pengetahuan pasien tentang pelayanan BPJS Kesehatan pada era JKN yaitu tingkat pengetahuan baik sebanyak 141 orang $(39,39 \%)$, tingkat pengetahuan cukup sebanyak 176 orang $(49,16 \%)$, dan tingkat pengetahuan kurang 41 orang $(11,45 \%)$. Persentase tingkat pengetahuan tertinggi adalah parameter iuran $(86,29 \%$; Kategori Baik) sedangkan persentasse pengetahuan terendah terletak pada parameter pelayanan obat (67,12\%; Kategori Cukup).

\section{UCAPAN TERIMA KASIH}

Penulis mengucapkan terimakasih kepada Akademi Farmasi ISFI Banjarmasin atas kontribusinya dalam pelaksanaan penelitian ini.

\section{DAFTAR PUSTAKA}

BPJS Kesehatan, 2018, 'Peserta Program JKN dan Fasilitas Kesehatan JKN', BPJS kesehatan, Diakses pada 1 Desember 2018, <https://bpjskesehatan.go.id/bpjs/home>.

BPJS, 2015, Buku Panduan Praktis Program Rujuk Balik bagi Peserta JKN, Jakarta, Humas.

Budiman \& Riyanto A, 2013, Kapita Selekta Kuisioner Pengetahuan Dan Sikap Dalam Penelitian Kesehatan, Salemba Medika, Jakarta, Indonesia,

Disastra, K.J., 2016, 'Pengetahuan Dan Sikap Masyarakat tentang Pelayanan BPJS Di Puskesmas Mangasana', Karya Tulis Ilmiah, Politeknik Kesehatan, Makasar.

Eky, F., 2015, 'Gambaran Kesesuain dan Ketidaksesuaian Resep Pasien BPJS Program Rujuk Balik Puskesmas Wilayah banjarbaru Periode Sepetember-Desember 2014', Karya Tulis Ilmiah, Akademi Farmasi ISFI, Banjarmasin.

Kemenkes, 2014, Peraturan Menteri Kesehatan Republik Indonesia Nomor 75 Tahun 2014 Tentang Pusat Kesehatan Masyarakat, Jakarta, Kementrian Kesehatan Republik Indonesia.

Nursalam. 2008. Konsep dan penerapan metodologi penelitian keperawatan. Jakarta 